\title{
MASP application in identifying the causes of delays in deliveries of UC's links projects
}

\section{Bruno Santos Corrêa ${ }^{1}$, Suane de Castro Paes ${ }^{2}$, Rosivan Cunha da Silva ${ }^{3}$, Maílson Batista de Vilhena $^{4}$}

\author{
1,2,3 Universidade Federal do Pará, Faculdade de Engenharia Industrial (FEI-UFPA) Abaetetuba, PA, Brazil \\ ${ }^{4}$ Universidade Federal do Pará, Programa de Pós-Graduação em Engenharia Química (PPGEQ-UFPA) Belém, PA, Brazil
}

Email: bruno27ni@hotmail.com, rosivan.cs@hotmail.com, vilhena2008@hotmail.com, suanecastro26@hotmail.com

Received: February $06^{\text {th }}, 2019$

Accepted: February $19^{\text {th }}, 2019$

Published: March $31^{\text {th }}, 2019$

Copyright (C2016 by authors and Institute of Technology Galileo of Amazon (ITEGAM).

This work is licensed under the Creative Commons Attribution International

License (CC BY 4.0).

http://creativecommons.org/licenses/by/4.0/ (c) (1) (3) Open Actes

\section{ABSTRACT}

This article demonstrates the use of the Analysis and Problem Solving Methodology (MASP), in identifying the causes of delays in the delivery of the consumer units (UC) projects, which are part of the Federal Government's Programa luz para todos (PLPT). The application of MASP was justified on the basis of the delay data of the company ETE, which operates in the construction of rural electrification distribution networks. With the application of MASP and quality tools the causes of the studied problem were discovered and from these it was possible to propose solutions for the reduction and elimination of the causes of delays of the UC projects.

Keywords: MASP, UC's, Rural electrification, Elimination of causes.

\section{Aplicação da MASP na identificação das causas de atrasos nas entregas dos projetos de ligações UC's}

\begin{abstract}
RESUMO
Este artigo demonstra a utilização da Metodologia de Análise e Solução de Problemas (MASP), na identificação das causas de atrasos nas entregas dos projetos de ligação de unidades consumidoras (UC's), que fazem parte do Programa luz para todos (PLPT) do governo federal. A aplicação da MASP foi justificada com base nos dados de atraso da empresa ETE, que atua na construção de redes de distribuição de eletrificação rural. Com a aplicação da MASP e ferramentas da qualidade foram descobertas as causas do problema estudado e a partir destas foi possível propor soluções para a redução e eliminação das causas de atrasos dos projetos de UC's.
\end{abstract}

Palavras chave: MASP, UC’s, Eletrificação rural, Eliminação das causas.

\section{INTRODUÇÃO}

No atual contexto em que se encontra o mundo corporativo, cada vez mais globalizado, onde a concorrência entre as organizações é cada vez mais acirrada, exige que estas tenham de se adaptar e de criar mecanismos para se enquadrarem e adequarem as suas estratégias a um mercado instável e em constante mudança, e cada vez mais competitivo. Assim, a gestão da qualidade torna-se um fator decisivo para as organizações, capaz de reduzir custos, tornar os processos produtivos mais eficientes e, por consequência, gerar mais lucros.

Um produto ou serviço de qualidade é aquele que atende perfeitamente, de forma confiável, acessível, segura e no tempo certo as necessidades do cliente. Desse modo, pode-se dizer que o produto ou serviço de qualidade é aquele projeto perfeito, de baixo custo, que garante segurança ao cliente, além de ser entregue no prazo, local e quantidade certa [1]

Existem diversas definições para o termo qualidade, o que torna impossível ter-se uma postura em definitivo para a ideia do que seja realmente qualidade [2].

A qualidade tem de ser desenvolvida visando diretamente seu público alvo. Para tanto, há de atender o consumidor quanto ao que ele deseja do produto ou serviço e quanto ao preço.

São princípios básicos da qualidade total reconhecer que toda organização tem problema, e que cada um deles é uma oportunidade de melhoria para pessoas, processos, produtos e sistemas. Para cada problema, a prioridade é identificá-lo em 
função de risco, custo e benefícios para negócios, para, assim, estabelecer um projeto de análise e soluções [3].

No universo da gestão da qualidade, uma das metodologias utilizadas para auxiliar os gestores na identificação dos problemas é a Metodologia de Análise e Solução de Problemas (MASP). Esta tem como foco a identificação dos problemas e, consequentemente, a elaboração de ações corretivas e preventivas de forma a eliminar ou minimizar os problemas detectados [4].

Alguns elementos são de extrema importância na utilização da MASP, porque contribuem para implantação de processos, como os dados e as informações, as ferramentas, o método estruturado e o trabalho em equipe [3].

A Metodologia de Analise e Soluções de Problemas pode ser aplicada durante o estado de rotina de um processo, quando o problema é detectado, por meio de alguma ferramenta de monitoramento. $\mathrm{O}$ ataque deve ser planejado e implantado, de modo a impedir o reaparecimento dos fatores causadores dos problemas, em busca de novas metas de desempenho do processo.

Assim, o presente trabalho tem por objetivo a aplicação da Metodologia de Análise e Solução de Problemas (MASP) e ferramentas da qualidade em uma empresa que presta serviços de edificação e ligação de Unidades Consumidoras para a concessionária de energia elétrica no estado do Pará, pois observou-se a necessidade de melhorias na qualidade do processo, de modo a propor soluções que permitam minimizar ao máximo os atrasos nas entregas dos projetos de instalação de UC's.

\section{REFERENCIAL TEÓRICO}

\section{II.1 QUALIDADE}

O desafio da qualidade tem se tornado um dos pontos fundamentais no mundo globalizado de competições. Atualmente, a qualidade é reconhecida nas organizações como uma estratégia, um diferencial competitivo capaz de reduzir custos, tornando mais eficientes os processos produtivos. Assim, a gestão da qualidade não significa apenas o controle da produção ou o uso de ferramentas e métodos de gestão, mas sim a qualidade passou a significar um modelo de gerenciamento que busca a eficiência organizacional.

Praticar um bom controle da qualidade é projetar, desenvolver, produzir e comercializar um produto de qualidade que é mais econômico, mais útil e sempre satisfatório para o consumidor.

As metas de qualidade são consequências das necessidades humanas ilimitadas e a capacidade de uma sociedade industrial para satisfazer as necessidades humanas [5].

Um produto ou serviço de qualidade é aquele que atende perfeitamente, de forma confiável, acessível, segura e no tempo certo as necessidades do cliente. Essas necessidades se tornam em metas de qualidade e geram submetas [1].

A qualidade é a conformidade com as especificações, a qual é medida pelo custo da não conformidade. A medida da qualidade é o preço da não qualidade [6].

A qualidade tem de ser desenvolvida visando diretamente seu público alvo. Para tanto, há de atender o consumidor quanto ao que ele deseja do produto ou serviço e quanto ao preço.

$\mathrm{O}$ controle da qualidade consiste em um processo de encontros das metas de qualidade estabelecidas durante as operações e usados para evitar ou corrigir eventos indesejáveis ou inesperados.
Para gerenciar os processos e, sobretudo, tomar as decisões com maior precisão, se faz necessário trabalhar com base em fatos e dados, ou seja, informações geradas no processo. Para tanto, existem técnicas importantes e eficazes, denominadas de ferramentas da qualidade, capazes de propiciar a coleta, o processamento e a disposição clara das informações disponíveis, ou dados relacionados aos processos gerenciados dentro das organizações. Em seguida são descritas algumas das principais ferramentas da qualidade.

\section{- Brainstorming}

Esta ferramenta, que em português significa tempestade de ideias, foi criada com o objetivo incentivar a participação dos colaboradores, em um local de reunião, a proporem ideias para algumas causas de problemas ou mesmo para o próprio problema [7].

\section{- Folha de verificação}

A folha de verificação é usada para facilitar a coleta e análise de dados. Seu uso economiza tempo e elimina o trabalho. É uma ferramenta onde as ações tomadas devem ser baseadas em cima dos dados, de forma que o problema possa ser claramente definido [8].

A folha de verificação é uma planilha para o registro de dados. O uso de uma folha de verificação torna a coleta de dados rápida e automática [9].

Inicialmente, é importante garantir a objetividade na recolha de dados, definindo com precisão quais os dados serão necessários recolher. O formulário elaborado deve ser bastante simples, onde as perguntas se encontrem perfeitamente definidas, as quais permitam a qualquer operador identificar de maneira rápida e correta quais os itens a registrar.

\section{- Estratificação}

A estratificação consiste no desdobramento de dados, a partir de um levantamento ocorrido, em categorias, grupos ou, melhor dizendo, estratos, para determinar sua composição [8].

Com a estratificação dos dados da folha de verificação é possível retratar de maneira bastante evidente qual a contribuição de cada uma das partes na composição do quadro da situação real.

\section{- Diagrama de Pareto}

A ideia do Diagrama de Pareto, também denominado de Regra do 80-20, é disponibilizar informações de maneira que se torne evidente e visual a identificação de todas as causas que influenciam diretamente no aumento de perdas de produção, principalmente as poucas causas que determinam muitas perdas, as quais se eliminadas diminuem substancialmente os desperdícios. As demais causas são relevadas de maneira preliminar, no entanto, se a causa de alguns poucos defeitos tem a solução simples, deve ser executada e eliminada imediatamente [7].

O diagrama de Pareto é utilizado para a identificação de problemas de uma maneira sistemática e quando se tem um grande número de problemas e recursos limitados para resolvê-los [10].

Nos problemas de qualidade a maioria das perdas deve-se a alguns poucos tipos de ocorrências, que podem ser atribuídos a uma pequena quantidade de causas. Se as poucas ocorrências vitais forem identificadas, podem-se eliminar quase todas as predas atacando as causas principais. Este tipo de problema ser resolvido de uma forma eficiente, através da utilização do diagrama de Pareto [11]. 


\section{- Diagrama de causa e efeito}

O diagrama de causa-efeito, também chamado diagrama de Ishikawa ou de espinha de peixe, é uma ferramenta simples muito utilizada em qualidade. É um processo que permite analisar e identificar as principais causas de variação do processo ou da ocorrência de um problema.

O diagrama de causa e efeito tem como finalidade explorar e indicar todas as causas possíveis de uma determinada condição ou um problema específico. Foi desenvolvido em 1943 por Kaoru Ishikawa, para representar a relação entre o efeito e todas as possibilidades de causa que podem contribuir para esse efeito [7].

O diagrama de causa e efeito é uma figura composta de linhas e símbolos, que representam uma relação significativa entre um efeito e suas possíveis causas [10].

Também permite que sejam sugeridas as causas de um problema para que possam ser formuladas sugestões de melhoria, estruturando as causas bem como seus efeitos sobre a qualidade. O diagrama é usado atualmente não apenas para lidar com as características da qualidade do produto, mas também em serviços [11].

\section{- Fluxograma}

O fluxograma é uma das primeiras ferramentas quando se pretende estudar, um processo, o caminho real para um produto ou serviço, com o objetivo de identificar os desvios. É o diagrama que tende a representar de uma forma simples, fácil e ordenada as várias fases do processo de fabricação ou de qualquer procedimento, funcionamento de equipamentos e sistemas. Os diagramas são constituídos por etapas sequenciadas de decisão e ação, onde cada um deles possui uma simbologia própria que ajuda a compreender o sistema de sua natureza: início ação, decisão, etc.

Grande parte da variação existente em um processo pode ser eliminada somente quando se conhece a sequência do processo de produção. Isto significa que as etapas influenciam na variabilidade final das características do produto ou serviço. Os fluxogramas podem ser aplicados a qualquer processo, desde o fluxo de materiais até as etapas de uma venda ou manutenção de um produto [10].

A utilização de fluxogramas permite identificar possíveis causas e origens dos problemas que ocorrem no processo de produção, verificando os passos desnecessários no processo, efetuando simplificações.

\section{- $5 W 2 H$ (Plano de ação)}

Esta ferramenta é utilizada principalmente no mapeamento e padronização de processos, na elaboração de planos de ação e no estabelecimento de procedimentos associados a indicadores [8].

A planilha $5 \mathrm{~W} 2 \mathrm{H}$ é uma ferramenta que auxilia no planejamento das ações que for desenvolver, ele é constituído de um relatório por colunas, cada uma delas acompanhadas por um título, palavras da língua inglesa: What (O que deve ser feito?), Why (Por que deve ser feito?), Who (Quem deverá fazer?), When (Quando deverá ser feito?), Where (Onde deverá ser feito?), How (Como deverá ser feito?) e How Much (Quanto custará?) [12].

Utiliza-se o 5W2H para assegurar e informar um conjunto de planos de ação, diagnosticar um problema e planejar ações. No quadro utilizado nesta ferramenta é possível visualizar a solução adequada de um problema, com possibilidades de acompanhamento da execução de uma ação. Buscando facilitar o entendimento através da definição de métodos, prazos, responsabilidades, objetivos e recursos.

\section{II.2 METODOLOGIA DE ANÁLISE E SOLUÇÃO DE PROBLEMAS - MASP}

No contexto do controle da qualidade total no Japão, surge a MASP (Metodologia de Análise e Solução de Problemas), um desdobramento do método gerencial intitulado ciclo PDCA. E de acordo com essa metodologia (MASP) um problema é definido como: "o resultado indesejável de um processo" [13].

O ciclo PDCA é um método utilizado para controlar e conseguir resultados eficazes e confiáveis nas atividades das organizações, de modo a apresentar melhorias nos processos. O método é composto por quatro etapas correspondente às letras da sigla (Plan - Planejar, Do - Executar, Check - Verificar, ActionAção corretiva) [2].

- Primeira etapa, Plan (Planejamento): Fase em que se definem as metas do processo analisado;

- Segunda etapa, Do (Execução): Necessária à educação e o treinamento das pessoas envolvidas, com a execução efetiva das ações planejadas. Paralelamente, as informações geradas no processo são registradas;

- Terceira etapa, Check (Verificação): Tem por objetivo comparar a execução, a partir dos dados registrados, com o planejamento. Pode-se notar se os resultados propostos inicialmente foram ou não alcançados;

- Quarta etapa, Action (Ação): Nesta fase a partir dos resultados alcançados, têm-se dois caminhos distintos a seguir: se a verificação mostrou que não foi possível atingir os resultados propostos, deve-se, então, partir para o estudo das ações corretivas e a seguir retornar ao ciclo PDCA; porém se os resultados propostos foram atingidos, deve-se então padronizar o processo, assegurando assim sua continuidade.

O PDCA permite criar, aprender, copiar e difundir conhecimento, sendo o aprendizado a alma de sua utilização, transformando a organização numa escola, pois a busca por resultados melhores é paralela à busca do conhecimento [1].

Assim, o ciclo PDCA é utilizado pelas organizações para gerenciar os seus processos internos de forma a garantir o alcance de metas estabelecidas, tomando as informações como fator de direcionamento das decisões. A Figura 1, representa o ciclo PDCA e sua dinâmica para o gerenciamento de processos.

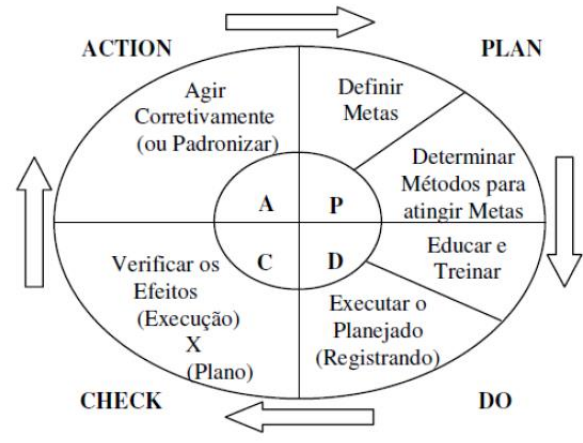

Figura 1: Método PDCA de Gerenciamento de Processos. Fonte: [1].

O MASP é uma ferramenta aplicada de forma sistemática contra uma situação insatisfatória ou para atingir um objetivo de melhoria estabelecido. Estas situações são identificadas, eliminadas ou melhoradas, através de etapas pré-determinadas, com base no ciclo PDCA [14]. 
A MASP, consiste em uma sequência de procedimentos racionais, baseada em fatos e dados, que visa levantar a causa fundamental de um problema para combatê-lo e eliminá-lo, ou seja, é utilizado para solucionar problemas diversos, sua utilização proporciona as organizações um processo de gestão voltada para ações corretivas e preventivas de forma a detectar os problemas e propor ações como foco na melhoria continua [12].

A Tabela 1, apresenta todas as etapas do MASP, tomando por base no PDCA, onde deve ser inserido num ciclo de melhoria contínua.

Tabela 1: Passos da Metodologia de Análise e Solução de Problemas.

\section{Metodologia de Analise e Solução de Problemas - MASP/QC Story}

\begin{tabular}{|c|c|c|c|}
\hline PDCA & Fluxograma & Fase & Objetivo \\
\hline \multirow{4}{*}{$\mathbf{P}$} & & $\begin{array}{l}\text { Identificação } \\
\text { do Problema }\end{array}$ & $\begin{array}{l}\text { Definir claramente } \\
\text { o problema e } \\
\text { reconhecer sua } \\
\text { importância. }\end{array}$ \\
\hline & & Observação & $\begin{array}{l}\text { Investigar as } \\
\text { características } \\
\text { especificas do } \\
\text { problema com } \\
\text { uma visão ampla e } \\
\text { sob vários pontos } \\
\text { de vista. }\end{array}$ \\
\hline & & Análise & $\begin{array}{l}\text { Descobrir as } \\
\text { causas } \\
\text { fundamentais. }\end{array}$ \\
\hline & & Plano de Ação & $\begin{array}{l}\text { Conceber um } \\
\text { plano para } \\
\text { bloquear as causas } \\
\text { fundamentais. }\end{array}$ \\
\hline $\mathbf{D}$ & & Execução & $\begin{array}{l}\text { Bloquear as causas } \\
\text { fundamentais. }\end{array}$ \\
\hline \multirow[t]{2}{*}{$\mathbf{C}$} & & Verificação & $\begin{array}{l}\text { Verificar se o } \\
\text { bloqueio foi } \\
\text { efetivo. }\end{array}$ \\
\hline & & $\begin{array}{l}\text { Bloqueio foi } \\
\text { Efetivo? }\end{array}$ & \\
\hline \multirow[b]{2}{*}{$\mathbf{A}$} & & Padronização & $\begin{array}{l}\text { Prevenir contra o } \\
\text { reaparecimento do } \\
\text { problema. }\end{array}$ \\
\hline & & Conclusão & $\begin{array}{l}\text { Recapitular todo o } \\
\text { processo de } \\
\text { solução do } \\
\text { problema para } \\
\text { trabalho futuro. }\end{array}$ \\
\hline
\end{tabular}

Fonte: [1].

As fases da MASP mostradas na Tabela 1, serão mais bem descritas a seguir:

- Identificação do problema: definir claramente o problema e mostrar que o problema em questão é relevante ou de importância maior do que outros problemas pertinentes. Assim, é preciso estabelecer critérios para a seleção de problemas. Por ex. prejuízo causado, risco, insatisfação do cliente, outros;

- Observação: investigar as características específicas do problema a partir de uma ampla gama de diferentes pontos de vista, quantitativos (dados) e qualitativos. Ir ao local onde ocorre o problema, observar e coletar informações necessárias que eventualmente não podem ser representadas na forma de dados. Deve-se ter um entendimento completo das características (especificidades) do problema;

- Análise: levantar, discutir e descobrir as causas fundamentais (causas básicas, causa raiz) do problema;

- Plano de Ação: elaborar um plano de ação a fim de bloquear (eliminar, aprisionar) as causas fundamentais identificadas no passo anterior. Nesta etapa pode-se usar o $5 \mathrm{~W} 2 \mathrm{H}$ para definir o plano de ação, ou seja, defina: o que, quando, quem, onde, porque será feito e como será feito. Definem-se as metas a serem atingidas e os controles para acompanhamento dos resultados obtidos;

- Ação: atuar para eliminar as causas fundamentais. Nesta etapa é muito importante que exista cooperação de todo o pessoal envolvido, para isso é preciso que as pessoas estejam devidamente treinadas e de acordo com as medidas (soluções) que estão sendo propostas;

- Verificação: verificar se o bloqueio da causa fundamental do problema foi efetivo, até certificar-se que o problema não ocorrerá novamente. Em caso de resposta negativa, deve-se retornar ao passo 2 ;

- Padronização: eliminar definitivamente a causa do problema para que ele não ocorra novamente. Identificar e realizar as alterações necessárias nos procedimentos de trabalho associados ao processo, para impedir a recorrência do problema. Treinar os envolvidos no novo procedimento;

- Conclusão: refletir sobre a experiência de aplicação da metodologia e verificar onde houve dificuldades e discuta o que deve ser aperfeiçoado no método para as próximas aplicações. Também se deve verificar os problemas remanescentes associados, e os que foram identificados ao longo da aplicação do método sobre o problema inicial. Por fim, discutir o que pode ser melhorado no método e problema estudado.

Se esses passos forem claramente entendidos e implementados nessa sequência, as atividades de melhoria dos processos serão consistentes do ponto de vista lógico e cumulativas ao longo do tempo. Esse método pode parecer uma maneira simplista de se resolver um problema, mas ao longo do tempo, ele demonstra ser a rota mais segura e curta, além de ser um método científico de análise de problemas.

A Metodologia de Análise e Solução de problemas pode ser aplicada tanto durante o estado de rotina de um processo, quando o problema é detectado por meio de alguma ferramenta de monitoramento, quanto no estágio de melhoria do processo, em busca de novas metas de desempenho. Assim, o ataque aos problemas deve ser planejado e implementado de modo a impedir o reaparecimento dos fatores causadores dos mesmos. Destaca que as ferramentas da qualidade são utilizadas durante o processo de aplicação do MASP [15]. 


\section{ESTUDO DE CASO}

O objeto de estudo desta pesquisa consiste na análise do serviço de construção redes de distribuição e eletrificação rural, prestado pela empresa ETE - Construções e Montagens Elétricas, à Concessionária de Energia Elétrica do estado do Pará. A empresa em questão, ETE, presta serviços de ligações de unidades consumidoras (UC's) nas comunidades em áreas rurais (construção de redes de distribuição de eletrificação rural).

Vale ressaltar que as ligações de UC's fazem parte do Programa Luz para Todos (PLPT) do governo federal, que tem como objetivo principal levar energia elétrica as comunidades isoladas, onde não há fornecimento de energia.

A empresa ETE é responsável por mapear comunidades rurais não atendidas no Estado do Pará, principalmente na região sudeste, pelo sistema de distribuição convencional de energia, vinculado ao Sistema Interligado Nacional (SIN). Ao identificar o não atendimento, é realizado um projeto inicial de levantamento de UC's e construção de rede necessária para o atendimento, e em seguida apresentado ao setor de projetos do PLPT da concessionária local. Caso o projeto seja aprovado, este é liberado para execução pela ETE, a qual passa a ser a responsável direta pelo mesmo. Caso contrário são realizadas sugestões de correções à empresa. A liberação dos projetos por parte da concessionária depende da análise de viabilidade econômica realizada pelos seus respectivos analistas de projeto. No entanto, durante diversos meses a ETE vem atrasando a entrega dos projetos de ligações UC's para a concessionaria de energia, devido ao não cumprimento de alguns requisitos no decorrer da etapa de execução dos projetos (liberados pela concessionária), merecendo destaque as seguintes questões: entrega de foto da placa de topologia, fotos ilegíveis (retrabalho), entre outros. Dessa forma, surge então à necessidade de se realizar um plano de melhoria da qualidade, e dentre as diversas ferramentas existentes, jugou-se mais adequada a utilização do MASP, pois esta permite identificar os problemas e implementar ações corretivas, além de identificar possíveis oportunidades de implementação de rotinas que venham a prevenir tais problemáticas.

\section{III.1 APRESENTAÇÃO DA EMPRESA}

Fundada em 19 de agosto de 1969, em Belém do Pará, a ETE vem atuando com destaque na implantação e na manutenção dos projetos mais importantes do Sistema de Telecomunicações do Brasil, desde o nascimento do Sistema Telebrás (1972). Da construção do cabo submarino Brasil-Canárias (1971), passando pela expansão da rede de telefonia de grande parte dos Estados brasileiros: Rio de Janeiro, São Paulo, Pará, Espírito Santo, Distrito Federal, Roraima, Amapá, Amazonas, Mato Grosso, Mato Grosso do Sul, Minas Gerais, Bahia, Goiás, Paraíba, Pernambuco, Rio Grande do Sul, Santa Catarina entre outros - até a construção dos atuais troncos ópticos, a ETE exibe presença cada vez mais significativa no mercado de telecomunicações, hoje muito competitivo.

O pioneirismo marca a atuação da ETE desde a sua fundação. A empresa foi a primeira a instalar fibras ópticas no Brasil; construiu o primeiro tronco óptico interurbano Rio - São Paulo; e, no Sistema Telebrás, em várias oportunidades inovou formas de trabalho, visando aumento de qualidade com redução de custos.

A competência e credibilidade conquistadas pela empresa no Brasil abriram as portas para voos internacionais. Entre outros trabalhos, a ETE desenvolveu o projeto completo das redes de telefonia de 58 cidades da Nigéria - inclusive a maior do país, Ibadan, e da capital Lagos - totalizando mais de 250.000 terminais.

Após a privatização do Mercado Nacional de Telecomunicações, participou do primeiro contrato no modelo SLA (Service Level Agreement) para a manutenção de rede de acesso telecomunicações, incluindo Voz, Telefonia Pública, Adsl (banda larga), Dados e troncos interurbanos de cabos ópticos.

Atualmente a ETE tem uma presença marcante no mercado de distribuição de energia elétrica, sendo um dos grandes construtores do Programa Luz para Todos do governo Federal, atuando nos estados do Pará, Maranhão e Rio Grande do Sul.

A seguir será descrito o processo objeto de estudo. Sendo assim vale ressaltar alguns dos envolvidos diretamente com ele: supervisor do projeto, analista do projeto e supervisor de cadastro, onde o este primeiro é responsável por acompanhar in loco toda a execução da obra junto à subcontratada, garantindo que esta seja realizada conforme planejado e dentro das especificações de projeto. O analista por sua vez é contato direto do supervisor e é responsável por atualizar o AS BUILT (documento em autocad que descreve o andamento do projeto) e garantir que todo desvio em relação ao projeto seja ajustado e/ou justificado a mudança de escopo. E por fim o supervisor de cadastro é o responsável direto por validar os cadastros que são encaminhados via sistema pelo supervisor e analista. A seguir será descrito como cada envolvido realiza suas tarefas dentro do cadastramento e ligação de novas UC's.

\section{III.2 PROCESSO OBJETO DE ESTUDO}

Dentro dos diversos processos realizados pela empresa ETE para o planejamento, abertura, execução e entrega dos projetos de eletrificação rural, destacam-se: medição, logística de materiais, fiscalização, cadastro e ligação de consumidores (UC's). A seguir cada processo é descrito de maneira simplificada, mas antes é importante destacar que a empresa ETE apesar de ser a responsável direta pelo projeto perante a cliente (CELPA), ela subcontrata a etapa de execução do projeto, ou seja, ela contrata outras empresas parceiras para construção da rede e ligação de consumidores em modalidade de "linha morta" (sem a presença de energia elétrica).

- Medição: é o processo pelo qual a obra (projeto) é faturada de maneira parcial e final, ou seja, é o momento em que a rede é medida fisicamente, onde cada componente tem seu valor específico, como por exemplo: cabeamento, instalação de postes, transformadores, chaves seccionadoras, aterramento e consumidores (medidores e Kit's do programa, 2 lâmpadas e 2 tomadas);

- Logística de materiais: constitui-se basicamente na entrega de todos os materiais necessários para construção da rede e ligação dos futuros consumidores. Além do recolhimento de sobra de materiais após o fim da etapa de fiscalização;

- Fiscalização: consiste no processo de inspeção técnica do projeto baseada nas normas e padrões aplicáveis à concessionária (e.g. NT.31.018.01 - Padrão de estruturas de redes de distribuição aérea compacta para $15 \mathrm{kV}$ e $36 \mathrm{kV}$ ) e é realizado após a conclusão do processo construtivo;

- Cadastro e ligação de consumidores: consiste no processo de integração de futuros consumidores ao sistema convencional 
de distribuição de energia elétrica (tanto virtualmente como fisicamente), sendo este o processo foco do trabalho.

Todo processo de cadastro começa com a análise de viabilidade de ligação do consumidor em um respectivo projeto. Em seguida os dados do futuro cliente são coletados por um colaborador da subcontratada responsável pela construção da rede e repassado para o supervisor da obra (colaborador da ETE), o qual por sua vez irá conferir se todos os dados obrigatórios estão preenchidos, se sim, o cadastro é digitado no sistema próprio da ETE e então este passará situação de "Pedido", conforme mostrado na Figura 2. Caso contrário o supervisor retorna o cadastro ao responsável pela coleta das informações e solicita a correção.

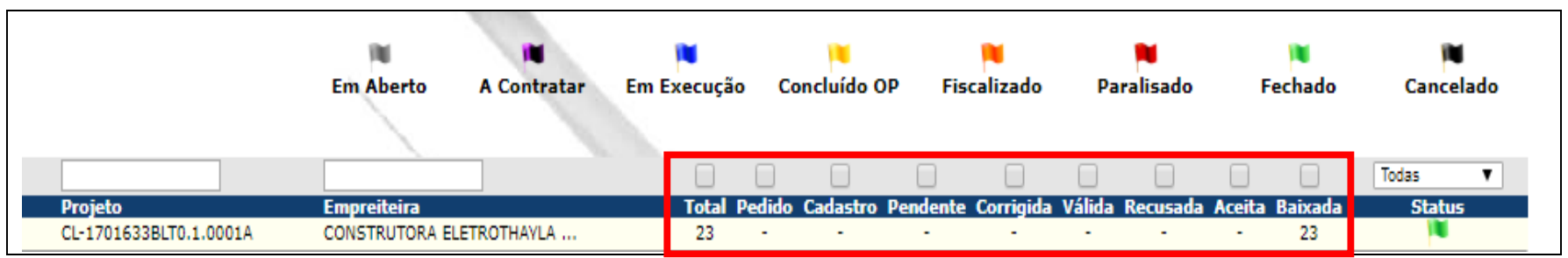

Figura 2: Fluxo do processo de cadastramento de futuros consumidores do programa PLPT.

Fonte: Sistema de informação da ETE, (2018).

Quando o cadastro entra no sistema, o analista responsável pela obra passa a complementar as informações, como: questões restritivas junto a receita federal no $\mathrm{CPF}$ do titular da futura conta contrato, localização do futuro consumidor, dados de medidor e transformador que atenderão o usuário e se será fornecido o KIT ao mesmo, informações estas que são oriundas do processo de planejamento de execução da obra realizado entre o supervisor e o analista via contato telefônico e relatório técnico. Além disso, neste momento o analista deve realizar o georeferênciamento (coordenadas de latitude e longitude via google earth) da obra e encaminhar ao setor de cadastro da ETE, o qual por sua vez verifica se já existe livro (identifica se há leiturista para região), caso não, o setor deverá solicitar ao departamento de UC's do PLPT da concessionária. Após esta etapa, os cadastros são passados para situação de "Cadastro", conforme se vê ainda na Figura 2.

Ao atingir $80 \%$ de obra construída (momento em que todos os consumidores devem estar interligados à rede) o analista confronta as informações dos cadastros de acordo com as fotos da instalação enviadas pelo supervisor da obra e a lista de materiais patrimoniados fornecida pelo setor de logística (via sistema), como transformador e medidor. Caso os dados estejam todos corretos o analista passa os cadastros para situação de "Corrigida", anexando informações importantes, como foto legível do medidor e do código identificador do transformador, instalados em campo, que atende aos consumidores (topologia).

Feito isso o cadastro passa a ser visualizado e estará disponível para validação pelo supervisor de cadastro, o qual irá conferir as informações preenchidas pelo analista e supervisor, observando as fotos anexadas e sua legibilidade. Além disso, ele também verifica se o número identificador do medidor não está duplicado com o banco de dados de todos os consumidores instalados pela concessionária. Caso esteja tudo correto e a CELPA já tenha fornecido o livro, os cadastros são validados e enviados ao setor responsável pelo PLPT-CELPA, passando para situação de "Válida". Caso seja encontrada alguma pendência e/ou divergência o cadastro é passado para "Pendente", e retorna para responsabilidade do analista.

Neste momento a responsabilidade passa a ser integralmente da concessionária, a qual inclui o consumidor em seu banco de dados, gera a respectiva conta contrato e "aceita" ou "recusa" o cadastro. Os únicos motivos pelos quais pode haver para situação de "recusada" é caso o consumidor possua alguma restrição cadastral em seu CPF ou haja duplicação ou não localização do código de identificação do medidor de energia. E por fim, quando o cadastro é entregue e digitado no SIN pela ELETROBRAS o consumidor é passado para "Baixada", conforme mostrado na Figura 2.

Conforme descrito, o sistema de cadastro e ligação de consumidores está relativamente bem estruturado, logo teoricamente deveria ser pouco provável que haja atraso nas entregas de UC's pela ETE à cliente CELPA. No entanto, na maioria dos meses a empresa ETE não vinha alcançando as metas estabelecidas pela concessionária, mesmo tendo carteira de obras suficiente para isso, com exceção do mês de outubro que a meta estipulada foi bem a baixo do normal devido questões burocráticas de liberação de novos projetos, e junto com os meses de fevereiro e março ela conseguiu superar as metas enviando cadastros que estavam pendentes do ano anterior, nos demais meses ela não conseguiu cumprir as metas UC's instaladas, conforme pode ser visto na Tabela 2 , dos dados históricos da empresa.

Tabela 2: Meta versus Realizado de UC's para o ano de 2016.

\begin{tabular}{|c|c|c|c|c|}
\hline \multirow{2}{*}{ Mês Ano } & Meta & \multicolumn{2}{|c|}{ Enviado } & \multirow{2}{*}{$\begin{array}{c}\text { Meta foi } \\
\text { alcançada }\end{array}$} \\
\cline { 3 - 4 } & Realizado & $\begin{array}{c}\text { Meta - } \\
\text { Realizado }\end{array}$ & Não \\
\hline fev/16 & 149 & 146 & 3 & Sim \\
\hline mar/16 & 106 & 213 & -107 & Sim \\
\hline abr/16 & 471 & 267 & 204 & Não \\
\hline mai/16 & 298 & 249 & 49 & Não \\
\hline jun/16 & 400 & 148 & 252 & Não \\
\hline jul/16 & 500 & 371 & 129 & Não \\
\hline ago/16 & 500 & 299 & 201 & Não \\
\hline set/16 & 346 & 324 & 22 & Não \\
\hline out/16 & 15 & 421 & -406 & Sim \\
\hline nov/16 & 300 & 282 & 18 & Não \\
\hline dez/16 & 300 & 292 & 8 & Não \\
\hline $\begin{array}{l}\text { Subtotal } \\
\text { de 2016 }\end{array}$ & 3.553 & 3.417 & 136 & Não \\
\hline
\end{tabular}

Fonte: Sistema Interno ETE, (2018). 
Na tabela acima podemos observar que a empresa não está conseguindo cumprir as metas mensais de ligações de UC's, as quais são definidas com base nos novos projetos liberados. Observando a diferença entre os subtotais, meta menos realizado, ao longo do ano de 2016, chegamos em um valor de 136 UC's pendentes, mas na realidade esse valor só foi possível graças as entregas de UC's, nos meses de fevereiro e março, que estavam pendentes desde o ano de 2015. A empresa não dispôs a explicar a quantidade de UC's do ano de 2015 que foram entregues no ano de 2016, ela só esclareceu que eles buscam sempre cumprir $100 \%$ os projetos, já que ela só recebe por projeto finalizado, ou seja, sem nenhuma UC's pendente. Portanto o subtotal de UC's pendentes no ano 2016 foi maior que 136.

\section{III.3 APLICAÇÃO DA MASP}

Neste trabalho as etapas da MASP serão aplicadas até a quarta etapa (plano de ação), em virtude do tempo da pesquisa, as etapas seguintes serão realizadas posteriormente.

Etapa 1 - Identificação do problema

Como dito anteriormente o processo de cadastro e ligação de consumidores será objeto deste estudo. E para um melhor entendimento do problema, atrasos nas estregas dos projetos de instalações UC's, enfrentado pela empresa ETE.

Para auxiliar na fundamentação da identificação do problema a empresa disponibilizou dados histórico de quatro projetos que estão atrasados, Tabela 3. Sendo que o universo de projetos atrasados não foi informado.
Tabela 3: Dados de projetos com UC's pendentes

\begin{tabular}{|ccc|}
\hline Projeto & $\begin{array}{c}\mathbf{N}^{\mathbf{0}} \text { de UC's com } \\
\text { pendências }\end{array}$ & $\begin{array}{c}\text { Porcentagem } \\
(\boldsymbol{\%})\end{array}$ \\
\hline DMT/15.00835A & 8 & 18 \\
DMT/15.00847A & 6 & 13 \\
BLT00.81A & 19 & 43 \\
DMT/15.00857A & 10 & 22 \\
\hline
\end{tabular}

Fonte: Autores, (2018).

As quantidades percentuais de UC's com pendencias são bastantes altas, chegando a $43 \%$ no projeto BLT00.81A, sendo que para a finalização dos projetos não deve haver nenhuma pendencia.

Estas pendencias acarretam maiores custos de nãoqualidade, como elevação do custo do processo ocasionado pela necessidade de retrabalhos.

Etapa 2 - Observação

Nesta fase, foi iniciada investigação das características específicas dos atrasos, com a finalidade de entender como eles ocorrem exatamente, identificando situações irregulares e potenciais causadores do problema em análise.

Essas evidências foram coletadas da planilha de dados, Figura 3, onde são lançadas todas as pendencias identificadas no processo, e serviram de base para a investigação e análise do problema, a fim de identificar as causas fundamentais.

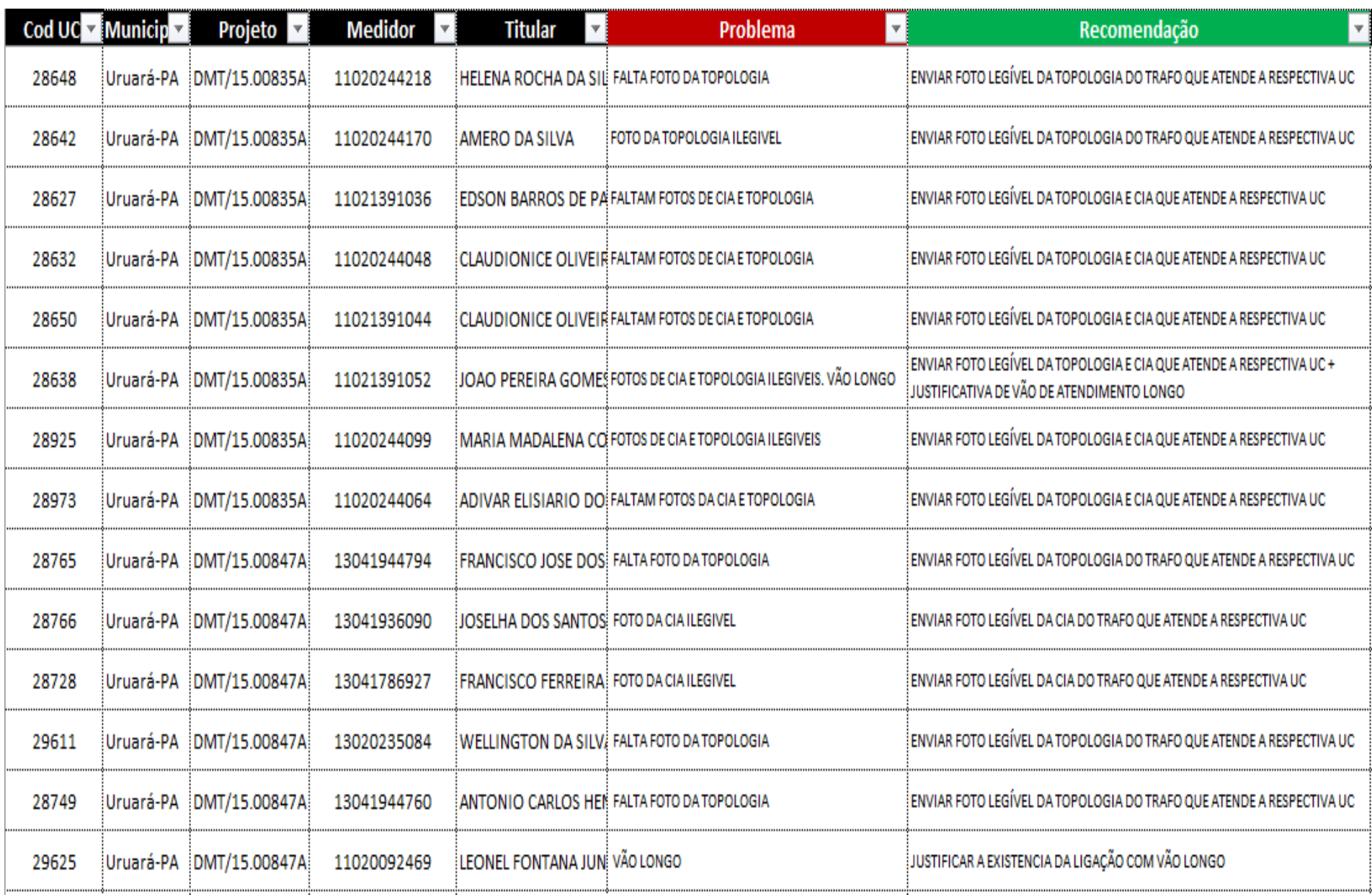

Figura 3: Print screen de parte da planilha de dados da empresa (ETE).

Fonte: Dados da empresa, (2018). 
Para uma exposição mais explícita das causas do problema analisado foi elaborada a Tabela 4, com os dados coletados, a fim de conhecer com clareza quais eram as pendências geradas durante o processo.

Tabela 4: Motivos de pendências.

\begin{tabular}{|l|c|c|}
\hline \multicolumn{1}{|c|}{ Pendencias } & $\mathbf{N}^{\mathbf{0}}$ de ocorrencias & Procentagem (\%) \\
\hline Falta inclusão do analista & 18 & 31,58 \\
\hline Falta foto de topologia/da placa de topologia & 10 & 17,54 \\
\hline Faltam fotos da cia e topologia & 4 & 7,02 \\
\hline Foto da cia ilegivel & 3 & 5,26 \\
\hline O supervisor informou que este medidor foi deslocado & 3 & 5,26 \\
\hline Ponto ainda não informada pelo supervisor & 2 & 3,51 \\
\hline Vão longo sem justificativa & 2 & 3,51 \\
\hline Falta informação do transformador & 1 & 1,75 \\
\hline Falta instalar placa de topologia & 1 & 1,75 \\
\hline Falta ponto do consumidor & 1 & 1,75 \\
\hline Falta ponto do consumidor e transformador no as built. & 1 & 1,75 \\
\hline Falta pont. de deriv. do consum./Falt. inform. do cabo de bt. & 1 & 1,75 \\
\hline Falta foto do medidor instalado em campo & 1 & 1,75 \\
\hline Falta informação do cabo de bt & 1 & 1,75 \\
\hline Fase b & 1 & 1,75 \\
\hline Falta inform. de derivação da bt. falta inform. de cabo da bt & 1 & 1,75 \\
\hline Foto da topologia ilegive & 1 & 1,75 \\
\hline Fotos de cia e topologia ilegiveis & 1 & 1,75 \\
\hline Fotos de cia e topologia ilegiveis. vão longo & 1 & 1,75 \\
\hline Falta informação de derivação de atendimento & 1 & 1,75 \\
\hline Vão longo & 1 & 1,75 \\
\hline Vão longo. faltam informações de cabo da bt. & 1 & 1,75 \\
\hline
\end{tabular}

Fonte: Autores, (2018).

Etapa 3 - Análise

Diante da necessidade de detectar qual ou quais as pendencias prioritárias a serem tratadas, utilizou-se o gráfico de Pareto, a partir dos dados da Tabela 4, pois esta ferramenta nos auxilia na identificação de todas as causas que influenciam diretamente nos atrasos de UC's, principalmente as poucas causas que determinam muitas pendencias, e eliminando-se as causas principais diminuem-se substancialmente o número de UC's com pendencias, consequentemente menor número de atrasos nas entregas dos projetos de ligações UC's.

O gráfico da Figrura 4 mostra as informações de maneira clara, evidente e visual quais são as principais causas do problema estudado, que são: falta inclusão do analista, com 31,58\% do total de pendências e falta foto de topologia/da placa de topologia, com $17,54 \%$ das pendências.

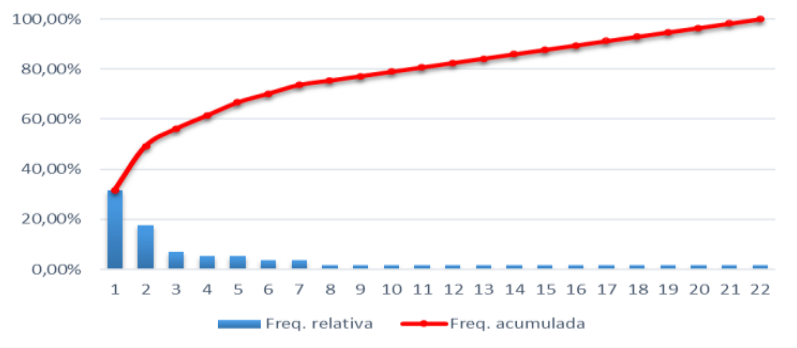

Figura 4 - Gráfico de Pareto das pendências.

Fonte: Autores, (2018).
Também foi elaborado um gráfico de rosca, Figura 5, para mostrar que 5 tipos de pendências (falta inclusão do analista, falta foto de topologia/da placa de topologia, faltam fotos da cia de topologia, foto da cia ilegível e supervisor informou que este medidor foi deslocado) são responsáveis por $66,67 \%$ do total dos atrasos nas entregas dos projetos de ligações UC's, registrados durante o processo de instalação de UC's.

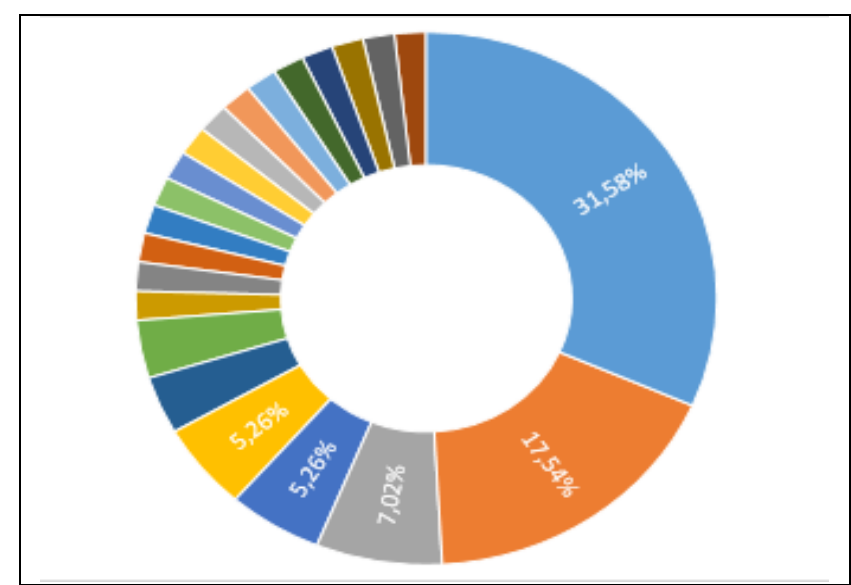

Figura 5: Gráfico de rosca. Fonte: Autores, (2018). 
Uma outra maneira de representar os dados da Tabela 4, seria agrupar as pendências que são semelhantes em sua origem (fotos com 37\%, falta de inclusão do analista com 32\%, falta informação com $19 \%$ e outros com 12\%), como mostra a Figura 6 , e assim poder representar as causas vitais que provocam os atrasos nas entregas dos projetos de ligações UC's.

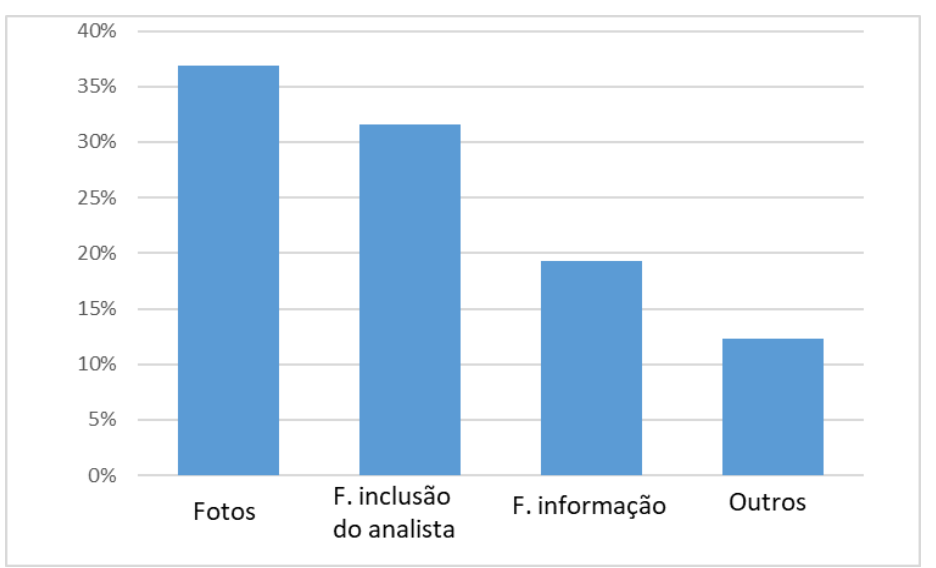

Figura 6: Problemas agrupados.

Fonte: Autores, (2018).

Analisando as Figuras 5 e 6, pode-se concluir que os principais problemas responsáveis por gerar pendencias operacionais de UC's são:

- Falta inclusão do analista, com $31,58 \%$ do total de ocorrências;

- Falta foto de topologia/da placa de topologia, com 17,54\% das ocorrências;
- E, faltam fotos da cia de topologia, foto da cia ilegível e supervisor informou que este medidor foi deslocado, os três somam $17,54 \%$ do total de ocorrências.

Através do agrupamento dos problemas que são semelhantes em sua origem, Figura 7 , pode-se evidenciar qual a contribuição de cada um, e assim poder representar as causas vitais que provocam os atrasos nas entregas dos projetos de ligações UC's.

- Fotos, foi o grupo que mais representou as causas vitais, com $37 \%$;

- Falta de inclusão do analista, representam $32 \%$ das causas vitais;

- Falta informação e outros, representam, respectivamente, $19 \%$ e $12 \%$ das causas vitais.

Com as informações que foram reunidas foi elaborado um plano de ação para bloquear as pendencias em UC's.

Etapa 4 - Plano de ação

Após a análise das causas fundamentais do problema estudado, elaborou-se um plano de ação, Tabela 5, utilizando-se a metodologia $5 \mathrm{~W} 1 \mathrm{H}$, ao invés de $5 \mathrm{~W} 2 \mathrm{H}$ por não ser possível estipular valores para execução das ações, priorizando as principais causas, por compreender que a eliminação dessas causas traria um benefício significativo para a redução dos atrasos nas entregas dos projetos de ligações UC's, e consequentemente a necessidade de retrabalhos. O objetivo deste plano de ação é apontar as principais causas e propor medidas para cessar ou minimizar o problema estudado.

Tabela 5: Plano de Ação para as principais causas.

\begin{tabular}{|c|c|c|c|c|c|}
\hline \multicolumn{6}{|c|}{ Plano de Ação - 5W1H } \\
\hline $\begin{array}{c}\text { What? } \\
\text { O que deve ser } \\
\text { feito? }\end{array}$ & $\begin{array}{c}\text { Why? } \\
\text { Por que deve ser } \\
\text { feito? }\end{array}$ & $\begin{array}{c}\text { Who? } \\
\text { Quem deverá } \\
\text { fazer? }\end{array}$ & $\begin{array}{l}\text { When? } \\
\text { Quando } \\
\text { deverá ser } \\
\text { feito? }\end{array}$ & $\begin{array}{c}\text { Where? } \\
\text { Onde deverá } \\
\text { ser feito? }\end{array}$ & $\begin{array}{c}\text { How? } \\
\text { Como deverá ser } \\
\text { feito? }\end{array}$ \\
\hline $\begin{array}{l}\text { Resolver } \\
\text { problemas } \\
\text { relacionados } \\
\text { com fotos }\end{array}$ & $\begin{array}{c}\text { Cumprir a meta } \\
\text { de ligações de } \\
\text { UC's }\end{array}$ & $\begin{array}{l}\text { Supervisores de } \\
\text { campo mais } \\
\text { próximos }\end{array}$ & 3 dias & $\begin{array}{l}\text { Nos locais de } \\
\text { ocorrências }\end{array}$ & $\begin{array}{l}\text { Verificar UC's } \\
\text { com pendencia e } \\
\text { ir em loco saná- } \\
\text { las }\end{array}$ \\
\hline $\begin{array}{l}\text { Inclusão do } \\
\text { analista }\end{array}$ & $\begin{array}{c}\text { Sanar as } \\
\text { pendencias }\end{array}$ & $\begin{array}{c}\text { Analista de } \\
\text { projeto }\end{array}$ & 2 dias & $\begin{array}{c}\text { ETE - base de } \\
\text { Belém }\end{array}$ & $\begin{array}{l}\text { Verificação - } \\
\text { correção }\end{array}$ \\
\hline $\begin{array}{c}\text { Resolver } \\
\text { problemas que } \\
\text { faltam } \\
\text { informações }\end{array}$ & $\begin{array}{c}\text { Cumprir a meta } \\
\text { de ligações de } \\
\text { UC's }\end{array}$ & $\begin{array}{l}\text { Supervisores de } \\
\text { campo mais } \\
\text { próximos }\end{array}$ & 3 dias & $\begin{array}{l}\text { Nos locais de } \\
\text { ocorrências, se } \\
\text { necessário }\end{array}$ & $\begin{array}{l}\text { Verificação e } \\
\text { correção }\end{array}$ \\
\hline $\begin{array}{l}\text { Resolver } \\
\text { demais } \\
\text { problemas }\end{array}$ & $\begin{array}{c}\text { Cumprir a meta } \\
\text { de ligações de } \\
\text { UC's }\end{array}$ & $\begin{array}{l}\text { Supervisores de } \\
\text { campo, Analista } \\
\text { de projeto e } \\
\text { Supervisores de } \\
\text { cadastro }\end{array}$ & 3 dias & $\begin{array}{l}\text { Nos locais de } \\
\text { ocorrências, se } \\
\text { necessário }\end{array}$ & $\begin{array}{l}\text { Verificação e } \\
\text { correção }\end{array}$ \\
\hline Treinamento & $\begin{array}{l}\text { Faze-los conhecer } \\
\text { a importância do } \\
\text { controle do } \\
\text { processo }\end{array}$ & $\begin{array}{c}\text { Os funcionários } \\
\text { efetivos }\end{array}$ & 1 mês & $\begin{array}{l}\text { ETE - bases } \\
\text { de Altamira e } \\
\text { Belém }\end{array}$ & $\begin{array}{l}\text { Através de } \\
\text { palestras }\end{array}$ \\
\hline
\end{tabular}

Fonte: Autores, (2018).

Como a empresa executa projeto em regiões isoladas de várias cidades do estado do Pará, seria inviável alocar um funcionário para resolver, por exemplo, os problemas com fotos. Ela verifica se tem alguma equipe realizando a execução de 
algum projeto nas proximidades que onde tem UC's com pendencias, então solicita que o supervisor mais próximo se desloque ao local das ocorrências para resolver as pendencias.

\section{Etapa 5 - Ação}

A execução deste Plano de Ação precisará ser acompanhada através de reuniões periódicas, objetivando a revisão e verificação da evolução de cada ação, bem como as dificuldades que surgirão para a execução de cada uma delas.

Etapa 6 - Verificação

Depois de descobrir as causas fundamentais foi desenvolvido um plano de ação para zerar ou minimizar ao máximo as pendencias das UC's. O plano de ação foi elaborado com o intuído de propor algumas ações corretivas para $\mathrm{o}$ melhoramento do processo através da ferramenta $5 \mathrm{~W} 1 \mathrm{H}$.

As ações a serem tomadas precisarão ser acompanhadas ao longo de sua implementação. Considera-se que se elas forem eficientes, apresentarão resultados satisfatórios com a redução no $\%$ de UC's com pendencias, consequentemente retrabalhos no processo.

Etapa 7 - Padronização

A padronização do processo ocorrerá se as ações de melhoria forem inseridas na rotina do processo da empresa, impedindo que as pendencias nas UC's voltem a se repetir. Assim, todos os procedimentos e ações de melhorias terão que fazer parte do dia a dia dos colaboradores.

\section{Etapa 8 - Conclusão}

Após aplicação da MASP tornou-se mais fácil detectar os problemas prioritários, secundários, e agir nas causas fundamentais do problema de atrasos nas entregas dos projetos de ligações UC's.

\section{CONCLUSÕES}

Após aplicar da Metodologia de Análise e Solução de Problemas (MASP), pode-se concluir que o método pode ser utilizado para solucionar problemas diversos. Também se comprovou que a MASP é uma metodologia simples, porém muito eficaz. Sua utilização no processo de gestão visa ações corretivas e preventivas de forma a detectar os problemas e propor ações com foco na melhoria contínua. Este trabalho foi desenvolvido dentro dos conceitos de gerenciamento da qualidade, e pelos dados apresentados anteriormente foi considerado eficaz, sendo seu principal objetivo alcançado, identificação das causas de atrasos nas entregas dos projetos de ligações UC's. Podemos, desta forma, concluir que o trabalho poderia beneficiar economicamente a empresa, pois todos os envolvidos no processo passariam a entender que a utilização da MASP com o auxílio das ferramentas da qualidade, como instrumento de melhoria contínua, podendo reduzir os custos dos processos.

\section{REFERÊNCIAS}

[1] V. F. Campos. TQC - Controle da Qualidade Total: no estilo japonês. $8^{\mathrm{a}}$ ed. Nova Lima, MG: INDG Tecnologia e Serviços, 2004.

[2] L. L. Marçal, A. C. A. Silva, N. N. Costa. Aplicação do MASP, utilizando o Ciclo PDCA na solução de Problemas no fluxo de Informações entre o PPCP e o Almoxarifado de uma fábrica de refrigerantes para o Abastecimento de tampas Plásticas e rolhas metálicas. Anais do ENEGEP - Encontro nacional de Engenharia de Produção, 2008.

[3] J. P. Cerqueira. A metodologia de Analise e Solução de Problemas. São Paulo: Pioneira, 1997.

[4] E. P. Paladini. Gestão da Qualidade: teoria e prática. $1^{\mathrm{a}}$ ed. São Paulo: Atlas, 2000.

[5] J. M. Juran. A Qualidade desde o Projeto. $3^{\mathrm{a}}$ ed. São Paulo: Pioneira, 1992.

[6] P. B. Crosby. Qualidade é investimento. 6ª ed. São Paulo: José Olympio, 1994.

[7] G. Vieira Filho. Gestão da Qualidade Total: uma abordagem prática. $2^{\mathrm{a}}$ ed. Campinas-SP: Alínea, 2010.

[8] I. Marshall Jr et al,. Gestão da Qualidade. $8^{\mathrm{a}}$ ed. Rio de Janeiro: FGV, 2007.

[9] S. Vieira. Estatística para a qualidade: como avaliar com precisão a qualidade em produtos e serviços. $1^{\text {a }}$ ed. Rio de Janeiro: Campus, 1999.

[10] A. W. Ramos. CEP para processos contínuos e em bateladas. $1^{\mathrm{a}}$ ed. Fundação Vanzolini, São Paulo: Edgard Blucher LTDA, 2000 .

[11] H. Kume. Métodos estatísticos para melhoria da qualidade. $11^{\mathrm{a}}$ ed. São Paulo: Gente, 1993.

[12] M. C. C. Werkema. As ferramentas da qualidade no gerenciamento de processos. $2^{\mathrm{a}}$ ed. Belo Horizonte: UFMG Fundação Christiano Ottoni, 1995.

[13] H. R. M. Hora, H. G. Costa. Tomada de Decisão do MASP: Uma Contribuição para Decisões Utilizando a Matriz AHP. Anais do ENEGEP - Encontro nacional de Engenharia de Produção, 2009.

[14] E. E. Arioli. Análise e solução de problemas: o método da qualidade total com dinâmica de grupo. $1^{\mathrm{a}}$ ed. Rio de Janeiro: Qualitymark, 1998.

[15] J. Z. N. Oliveira, J. C. Toledo. Metodologia de análise e solução de problemas (MASP): estudo de caso em uma empresa de pequeno porte do setor eletroeletrônico; Anais do XV SIMPEP - Simpósio de Engenharia de Produção, 2008. 